\title{
Angka Kebuntingan Kerbau Rawa (bubalus bubalis) menggunakan Hormon sinkronisasi yang berbeda
}

\author{
Heru Gunawan ${ }^{1}$, Muhamad Rodiallah ${ }^{1}$, Yendraliza ${ }^{1, a}$ \\ ${ }^{1}$ Fakultas Pertanian dan Peternakan Universitas Islam Negeri Sultan Syarif Kasim Riau Jl. HR. \\ Soebrantas KM. 15 No. 155, Panam, Pekanbaru 28193, Indonesia \\ aemail: yendraliza@uin-suska.ac.id
}

\begin{abstract}
Abstrak
Tujuan dari penelitian ini adalah untuk mencari metode sinkronisasi yang dapat meningkatkan angka kebuntingan pada kerbau rawa di Kabupaten Kuansing. Penelitian ini menggunakan 9 ekor ternak kerbau betina yang tidak bunting dan dibagi dalam 3 kelompok. Kelompok pertama di injeksi dengan GnRH pada hari pertama, diikuti injeksi PGF2 $\alpha$ pada hari ke-7 pasca injeksi GnRH. Pengamatan dilakukan pada hari ke-8. Kelompok kedua di injeksi PGF2 $\alpha$ pada hari pertama, diikuti injeksi PGF2 $\alpha$ pada hari ke-11. Pengamatan dilakukan pada hari ke-12. Kelompok ketiga diinjeksi dengan PGF2 $\alpha$ pada hari pertama dan pengamatan dilakukan pada hari ke-8. Ternak kawinkan dengan metode inseminasi buatan (IB) setelah terlihat tanda-tanda estrus dengan straw $0.5 \mathrm{ml}$ dari BIB Tuah Sakato. Data di analisis dengan Rancangan Acak Kelompok (RAK). Peubah yang diukur adalah kecepatan estrus, lama estrus, intensitas estrus, persentase estrus dan persentase kebuntingan. Hasil penelitian menunjukkan bahwa penggunaan kombinasi hormon GnRH + PGF2 $\alpha$ pada kerbau rawa di Kuansing menghasilkan persentase kebuntingan tertinggi (100\%), estrus lebih cepat (53.67 jam), 100\% estrus, dengan lama estrus 13.5 jam dan score intensitas estrus tertinggi $(+++)$. Sebagai kesimpulan; sinkronisasi menggunakan GnRH dan PGF2 $\alpha$ merupakan kombinasi terbaik guna meningkatkan angka kebuntingan kerbau rawa di Kuansing.
\end{abstract}

Kata kunci : bunting, estrus, kerbau rawa

\section{The pregnancy rate of Swamp buffalo (bubalus bubalis) on different synchronizing hormones}

\begin{abstract}
Abstrack
The aim of this study is to find out the synchronization method that can be increased the pregnancy rate of swamp buffalo in Kuansing Regency. This study used nine female buffalo who did not pregnant and was divided into 3 groups. The first group was injected with GnRH on the day-1, followed by PGF2 $\alpha$ on the day-7. Observations were made on the day-8. The second group was injected $P G F 2 \alpha$ on the day-1, followed by $P G F 2 \alpha$ injection on the day-8. Observations were made on the day-11. The third group was injected with PGF $2 \alpha$ on the day-1 and assessment was carried out on the day-8. Buffalo is then mated with Artificial Insemination method (AI) after visible signs of estrus with $0.5 \mathrm{ml}$ of straw from AI center Tuah Sakato. Data were analyzed by Randomized Block Design (RBD).The parameter of this study are estrous velocity, estrus duration, estrous intensity, estrus percentage and pregnancy rate. The results of this study seen that using combination of the GnRH + PGF2 $\alpha$ hormone in swamp buffaloes in Kuansing produced the highest percentage of pregnancy (100\%), onset estrus (53.67 hours), $100 \%$ of estrus, with the duration of estrus of 13.5 hours and high estrus scores were obtained $(+++)$. As an conclusion, that the combination of GnRH and PGF is the best combination to increased of pregnancy rate buffalo swamps in Kuansing.
\end{abstract}

Keywords: estrus, pregnancy, swamp buffalo. 


\section{Pendahuluan}

Kerbau merupakan salah satu ternak lokal yang memiliki sejumlah keunggulan dan memberi banyak manfaat khususnya bagi petani dan peternak (Komariah et al., 2015). Kerbau tersebar hampir di seluruh wilayah Indonesia. Kabupaten kuantan singingi memiliki populasi kerbau terbesar kedua setelah kabupaten kampar di Provinsi Riau. Perkembangan populasi ternak kerbau di Kabupaten Kuantan Singingi tidak mengalami peningkatan. Hal ini terlihat dari jumlah populasi dari tahun 2015 sebanyak 10.351 ekor, sedangkan pada tahun 2016 hanya 10.231 ekor (BPS, 2017).

Salah satu penyebab permasalahan ini adalah reproduksi (Yendraliza et al., 2010). Selain itu populasi juga dipengaruhi oleh faktor lingkungan, gizi dan manajemen yang dilakukan oleh peternak (Nanda et al., 2003). Solusi peningkatan populasi ini adalah inseminasi buatan. Kendala utama yang dirasakan menghambat pelaksanaan inseminasi buatan adalah sulitnya deteksi berahi karena gejala berahi umumnya tidak jelas atau berahi tenang (silent heat) (Mohammed, 2018). Mufiidah et al. (2013) menyatakan bahwa sulitnya deteksi berahi pada kerbau disebabkan karena peternak masih melakukan sistem pemeliharaan yang ekstensif dan kebiasaan ternak kerbau yang suka berkubang. Pelaksanaan IB membutuhkan deteksi estrus yang tepat. Tanda-tanda estrus yang jelas dapat dimunculkan dengan sinkronisasi (Pursley et al., 1998). Kualitas estrus yang baik dilihat dari produksi lendir vagina yang jernih, yang menandakan memiliki folikel yang besar serta menghasilkan estrogen yang tinggi (Balumbi et al., 2019). Beberapa laporan memberikan persentase estrus dan angka kebuntingan yang kontradiktif tentang penggunaan hormone sinkronisasi pada ternak kerbau (Purohit et al., 2019). Neglia et al. (2018) menyatakan bahwa penggunaan GnRH dan PGF2 $\alpha$ menghasilkan 81\% kebuntingan, sedangkan (Malik et al., 2013) menyatakan injeksi single $\mathrm{PGF}_{2 \alpha}$ hanya menghasilkan $76 \%$ kebuntingan pada sapi Bali. Penggunaan injeksi ganda $\mathrm{PGF}_{2 \alpha}$ terbukti dapat menimbulkan respon estrus sebesar 95\% pada sapi Bali (Saili et al., 2016). Perbedaan ini menjadi dasar untuk melihat angka kebuntingan kerbau lumpur di Kuansing pada jenis hormone sinkronisasi yang berbeda.

\section{Materi dan Metode}

Penelitian ini dilaksanakan pada bulan Agustus 2019 - November 2019 di Desa Sawah Kecamatan Kuantan Tengah Kabupaten Kuantan Singingi. Penelitian ini menggunakan 9 ekor kerbau betina yang sudah pernah melahirkan dengan rataan umur 3,5-4 tahun, 4-5 tahun, $>5$ tahun dan BCS 3-4. Bahan yang digunakan adalah GnRH $\left(\right.$ Fertagyl $^{\circledR}$ ) dan hormon PGF $_{2 \alpha}$ $\left(\right.$ Capriglandin $\left.^{\mathbb{B}}\right)$. Dosis GnRH yang diberikan adalah $3 \mathrm{ml}$ (Yendraliza et al., 2012). Dosis $\mathrm{PGF}_{2 \alpha}$ adalah $2.5 \mathrm{ml}$ (sesuai petunjuk pemakaian). Semua kerbau dipelihara dengan sistem semi ektensif pada peternakan rakyat di desa Sawah. Ternak digembala pada siang hari dan dikandangkan pada malam hari tanpa pakan tambahan. Ternak diseleksi dengan cara palpasi rektal oleh dokter hewan. Ternak yang memiliki corpus luteum dan tidak bunting ditempatkan dalam satu kandang.

Metode yang digunakan dalam penelitian ini adalah metode eksperimen dengan menggunakan Rancangan Acak Kelompok. Kerbau betina di kelompokkan berdasarkan umur ternak 3,5-4 tahun, 4-5 tahun, $>5$ tahun. Kelompok pertama diberi GnRH (Fertagyl $\left.{ }^{\circledR}\right) 3 \mathrm{ml}$ pada hari pertama dan $\mathrm{PGF}_{2 \alpha}$ (Capriglandin $\left.^{\circledR}\right) 2.5 \mathrm{ml}$ di hari ke-7 (gambar 1). Pengamatan estrus dilakukan pada hari ke-2 setelah injeksi $\mathrm{PGF}_{2 \alpha}$. Kelompok kedua di beri $\mathrm{PGF}_{2 \alpha}$ $\left(\right.$ Capriglandin $\left.^{\circledR}\right) 2.5 \mathrm{ml}$ pada hari pertama dan $\mathrm{PGF}_{2 \alpha}$ (capriglandin $^{\circledR}$ ) $2.5 \mathrm{ml}$ kembali di hari ke-11 (Gambar 2). Pengamatan estrus pada kelompok kedua dilakukan pada hari ke-12. Kelompok ketiga hanya diberi 1 kali $\mathrm{PGF}_{2 \alpha}\left(\right.$ Capriglandin $\left.^{\circledR}\right) 2.5 \mathrm{ml}$ (Gambar 3). Pengamatan estrus dilakukan pada hari ke-3. Semua hormon yang diberikan pada ternak kerbau diinjeksikan secara intramuscular 

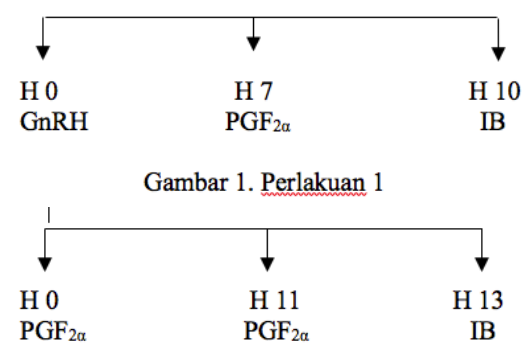

Gambar 1. Perlakuan 2

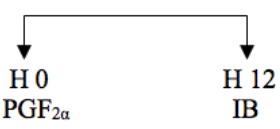

Gambar 1. Perlakuan 3

Kerbau betina yang memperlihatkan estrus ditandai dengan perubahan tingkah laku dari tenang menjadi gelisah, keluarnya lendir dari vulva dan terjadinya perubahan vulva seperti bengkak dan bewarna merah. Inseminasi dilakukan 18 jam setelah ciriciri estrus terlihat menggunakan metode IB dengan konsentrasi sperma 50 juta. Semen yang digunakan berasal dari BIB Tuah sakato, Payakumbuh, Sumatera Barat. Pemerikasaan kebuntingan dilakukan 60 hari setelah IB dengan cara palpasi rektal oleh petugas pemeriksa kebuntingan Dinas Peternakan Kuansing.

Peubah yang diukur adalah 1). Intensitas estrus (perubahan tingkah laku estrus dengan nilai score 3 jika semua kerbau betina per perlakuan memperlihatkan gejala estrus, score 2 jika semua kerbau betina per perlakuan hanya memperlihat perubahan vulva dan keluar lendir, score 1 jika semua kerbau betina per perlakuan hanya memperlihatkan perubahan vulva. 2). Kecepatan munculnya estrus (waktu yang dibutuhkan dari penyuntikan PGF2 $\alpha$ terakhir sampai munculnya tanda-tanda estrus (jam). 3). Lama estrus (interval antara waktu dari penampakan tanda-tanda estrus dengan berakhirnya estrus yang ditandai dengan tidak adanya lendir yang menggantung di vulva (jam)). 4). Persentase estrus (jumlah ternak betina yang estrus dibagi jumlah betina yang mendapat perlakuan di kali 100). 5). Persentase kebuntingan (jumlah betina yang bunting dibagi dengan jumlah betina yang di IB di kali 100). Analisis data Pengaruh antar perlakuan di analisis menggunakan rancangan acak kelompok (RAK) (Steel et al., 1991).

\section{Hasil dan Pembahasan \\ Intensitas Estrus}

Intensitas kerbau rawa di Kuansing lebih baik pada perlakuan $\mathrm{GnRH}+\mathrm{PGF}_{2 \alpha}$ dari pada perlakuan $\mathrm{PGF}_{2 \alpha}+\mathrm{PGF}_{2 \alpha}$ dan perlakuan $\mathrm{PGF}_{2 \alpha}$ saja (Tabel 1). Hal ini ditandai dengan munculnya semua gejala estrus pada perlakuan $\mathrm{GnRH}+\mathrm{PGF}_{2 \alpha}$ yaitu keluarnya lendir, vulva membengkak, warna menjadi merah, lebih hangat dan diam saat dinaiki oleh ternak lain. Pemberian GnRH diawal perlakuan memberikan efek pada ovarium kerbau betina dalam siklus yang sama sehingga penggunaan $\mathrm{PGF}_{2 \alpha}$ setelahnya dapat memberikan pengaruh yang optimal dalam memunculkan estrus (Pursley et al., 1997). $\mathrm{GnRH}$ akan memicu pelepasan LH (luitinizing hormone) menyebabkan ovulasi dan memulai gelombang folikel baru (Kaim et al., 2003). Intensitas kerbau rawa di Kuansing ini berbeda dengan intensitas estrus sapi Aceh menggunakan kombinasi CIDR dan PGF $_{2 \alpha}$ (Siregar et al., 2015). Perbedaan ini disebabkan jenis ternak yang berbeda, hormone yang digunakan berbeda dan respon individu terhadap hormone sinkronisasi juga berbeda (Hashemi \& Safdarian, 2017)

Tabel 1. Intensitas estrus kerbau Rawa di Kuansing menggunakan metode sinkronisasi yang berbeda

\begin{tabular}{ccccc}
\hline Perlakuan & Skor & $\mathrm{n}$ & Intensitas Estrus & Keterangan \\
\hline $\begin{array}{c}\mathrm{A} \\
\mathrm{GnRH}+\mathrm{PGF}_{2 \alpha}\end{array}$ & +++ & 3 & Tinggi & $\begin{array}{c}\text { Vulva membengkak, merah, } \\
\text { hangat, dan diam bila dinaiki. } \\
\text { Vulva membengkak, merah, } \\
\mathrm{PGF}_{2 \alpha}+\mathrm{PGF}_{2 \alpha}\end{array}$ \\
$\begin{array}{c}\mathrm{C} \\
\mathrm{PGF}_{2 \alpha}\end{array}$ & ++ & 3 & Sedang & $\begin{array}{c}\text { hangat. } \\
\text { Vulva membengkak dan } \\
\text { hangat. }\end{array}$ \\
\hline
\end{tabular}

Tabel 2. Kecepatan Estrus Kerbau Rawa pada Hormon Sinkronisasi yang Berbeda (jam). 


\begin{tabular}{llllll}
\hline Metode sinkronisasi & $\begin{array}{l}\text { Onset } \\
\text { (jam) }\end{array}$ & Estrus & $\begin{array}{l}\text { Lamannya estrus } \\
\text { (jam) }\end{array}$ & $\begin{array}{l}\text { Persentase } \\
\text { estrus (\%) }\end{array}$ & $\begin{array}{l}\text { Persentase } \\
\text { Kebuntingan (\%) }\end{array}$ \\
\hline$\left(\mathrm{GnRH}^{\mathrm{P}}+\mathrm{PGF}_{2 \alpha}\right)$ & $53.67^{\mathrm{a}} \pm 7.68$ & $13.5^{\mathrm{a}} \pm 6.5$ & $100^{\mathrm{a}}$ & $100^{\mathrm{a}}$ \\
$\left(\mathrm{PGF}_{2 \alpha}+\mathrm{PGF}_{2 \alpha}\right)$ & $50.46^{\mathrm{a}} \pm 6.20$ & $15.5^{\mathrm{a}} \pm 5.5$ & $100^{\mathrm{a}}$ & $66^{\mathrm{b}}$ \\
$\left(\mathrm{PGF}_{2} \alpha\right)$ & $63.18^{\mathrm{b}} \pm 1.30$ & $17.3^{\mathrm{b}} \pm 3.3$ & $80^{\mathrm{b}}$ & $33^{\mathrm{c}}$ \\
\hline
\end{tabular}

Keterangan : Data disajikan dalam rata-rata \pm standard deviasi.

\section{Kecepatan Estrus}

Rata-rata kecepatan estrus kerbau rawa menggunakan hormon sinkronisasi yang berbeda berpengaruh nyata $(\mathrm{P}>0,05)$ (Tabel 2). Injeksi hormon $\mathrm{PGF}_{2 \alpha}$ tunggal pada kerbau rawa di Kuansing menghasilkan kecepatan estrus yang lebih lama dibandingkan dengan kombinasi injeksi hormone $\mathrm{GnRH}+\mathrm{PGF}_{2 \alpha}$ dan $\mathrm{PGF}_{2 \alpha}+\mathrm{PGF}_{2 \alpha}$ (63.18 \pm 1.8 Jam VS 50.46 jam- 53.67jam). Perbedaan ini disebabkan oleh respon individu ternak terhadap hormone yang digunakan berbeda. Sesuai dengan pernyataan (Islam, 2011) yang mengatakan bahwa setiap ternak akan memberikan respon yang berbeda pada penggunaan hormone sinkronisasi. Pemberian GnRH akan menghasilkan siklus berahi yang baik karena GnRH akan mempengaruhi aktivitas ovarium (Noseir, 2003). Selanjutnya GnRH akan menstimulasi FSH untuk merangsang perkembangan folikel dan merangsang pelepasan LH untuk ovulasi sampai terbentuk CL (Keskin et al., 2010)

Kecepatan estrus kerbau Kuansing ini berbeda dengan kecepatan estrus sapi Bali (50.46 jam - 63.18 jam VS 61.25 jam63.67 jam) (Malik et al., 2018). Perbedaan ini disebabkan jenis ternak, hormone dan fase estrus individu ternak yang digunakan berbeda. Selain itu ukuran tubuh ternak dan kondisi fisiologis ternak sangat mempengaruhi efisiensi dari hormone sinkronisasi (Hafez et al., 2000).

\section{Lamanya Estrus}

Penggunaan hormone PGF2 $\alpha$ tunggal pada kerbau betina di Kuansing lebih lama di bandingkan penggunaan ganda hormone PGF $2 \alpha$ dan kombinasi hormone GnRH dan PGF2 $\alpha$. 17.3 jam VS 13.5 jam- 15.5 jam) (Tabel 2). Hal ini kemungkinan disebabkan oleh penambahan $\mathrm{GnRH}$ dan penggunaan PGF $2 \alpha$ yang ganda mempengaruhi lama kerja PGF2 $\alpha$. hal ini sejalan dengan (Ferraz et al., 2017) yang menyatakan bahwa penggunaan GnRH akan memudahkan kerja PGF2 $\alpha$ dalam melisis corpus luteum.

Lama estrus kerbau betina di Kuansing berbeda dengan kerbau betina di Kampar (10.4 jam- 18 jam) (Yendraliza et al., 2012). Hal ini disebabkan karena hipofisa anterior pada kerbau induk yang disinkronisasi merespon terhadap penyuntikan GnRH serta PGF2 $\alpha$ ganda akan menstimulasi hipofisa anterior untuk mensekresi FSH dan LH. FSH bekerja pada tahap awal perkembangan folikel. FSH dan LH merangsang folikel ovarium untuk mensekresi estrogen. Menjelang waktu ovulasi konsentrasi hormon estrogen mencapai suatu tingkatan yang cukup tinggi untuk menekan produksi FSH dan dengan pelepasan LH menyebabkan terjadinya ovulasi dengan menggertak pemecahan dinding folikel dan pelepasan ovum (Hafez et al., 2000).

\section{Persentase Estrus}

Persentase estrus kerbau betina di Kuansing lebih tinggi pada penggunaan kombinasi $\mathrm{GnRH}+\mathrm{PGF} 2 \alpha$ dan penggunaan PGF2 $\alpha$ ganda dibandingkan dengan penggunaan PGF2 $\alpha$ tunggal (Tabel 2). Hal ini disebabkan oleh Suntikan GnRH pada sapi dan kerbau akan menstimulasi FSH untuk merangsang perkembangan folikel dan merangsang pelepasan LH untuk ovulasi sampai terbentuk CL, sehingga PGF2 $\alpha$ dapat bekerja dengan baik (Purohit et al., 2019).

Persentase estrus pada kerbau di Kuansing ini berbeda dengan persentase estrus sapi Bali di NTB yang menghasil $100 \%$ estrus pada semua perlakuan homon progesterone (Mardiansyah et al., 2016). Berbeda dengan persentase estrus sapi-sapi potong laktasi yang disinkronisasi dengan PGF $2 \alpha$ hanya menghasilkan $87 \%$ estrus (Hafizuddin et al., 2012). Perbedaan ini disebabkan jenis ternak, kondisi fisiologis dan hormone yang digunakan berbeda. 
Pursley et al., (1997) menyatakan bahwa tubuh ternak akan memberikan respon yang berbeda pada setiap hormone sikronisasi. Ditambahkan oleh (Hafizuddin et al., 2012) bahwa kondisi ovarium ternak saat pemberian hormone sangat mempengaruhi efisiensi protocol sinkronisasi.

\section{Persentase Kebuntingan}

Persentase kebuntingan kerbau rawa di Kabupaten Kuantan Singingi lebih tinggi pada perlakuan kombinasi GnRH+PGF2 $\alpha$ $(100 \%)$ dan perlakuan PGF2 $\alpha$ ganda $(66 \%)$ dibandingkan dengan perlakuan PGF2 $\alpha$ tunggal (33\%) (Tabel 2). Perbedaan ini disebabkan oleh berbedanya intensitas estrus dan persentase estrus pada setiap perlakuan. (Gordon, 2017) menyatakan bahwa keberhasilan kebuntingan di pengaruhi oleh tanda-tanda estrus yang jelas.

Persentase kebuntingan kerbau rawa di Kabupaten Kuantan Singingi berbeda dengan kerbau rawa di Kalimantan Selatan (75\%) (Rizal \& Riyadhi, 2017) dan persentase kebuntingan kerbau Simalue Aceh (70\%) (Samsuandi et al., 2016). Persentase kebuntingan kerbau Kuansing pada perlakuan kombinasi GnRH + PGF2 $\alpha$ $(100 \%)$ lebih tinggi dibandingkan persentase kebuntingan kerbau di Italy (36\%) (Barile, 2012). Persentase kebuntingan kerbau di Kuansing pada perlakuan PGF $2 \alpha$ ganda $(66 \%)$ lebih rendah dari persentase kebuntingan kerbau di Thailand (80\%) (Jamsawat et al., 2015). Perbedaan persentase kebuntingan ini disebabkan oleh umur ternak, jenis hormon, sistem pemeliharaan dan lingkungan yang digunakan berbeda (Praharani \& Sianturi, 2018).

Angka kebuntingan ditentukan oleh kesuburan pejantan, kesuburan betina dan teknik inseminasi. (Sanker et al., 2014) menjelaskan bahwa tinggi rendahnya angka kebuntingan dipengaruhi oleh kondisi ternak, deteksi birahi, dan pengelolahan reproduksi.

\section{Kesimpulan}

Penggunaan kombinasi hormon GnRH + PGF2 $\alpha$ pada kerbau rawa di Kuansing menghasilkan persentase kebuntingan tertinggi (100\%), estrus lebih cepat (53.67 jam), $100 \%$ estrus, dengan lama estrus 13.5 jam dan score intensitas estrus tertinggi $(+++)$.

\section{Ucapan Terimakasih}

Ucapan terimakasih kepada Rektor UIN Suska Riau atas dana penelitian tahun 2018 dan peternak yang telah bersedia menyediakan ternak kerbau penelitian serta petugas lapangan Dinas Peternakan Kuansing,

\section{Daftar Pustaka}

Balumbi, M., Supriatna, I., \& Setiadi, M. A. (2019). Respons dan Karakteristik Estrus setelah Sinkronisasi Estrus dengan Cloprostenol pada Sapi Friesian Holstein. Acta VETERINARIA Indonesiana, 7(1), 29-36.

https://doi.org/10.29244/avi.7.1.29-36

Barile, V. L. (2012). Technologies Related with the Artificial Insemination in Buffalo. Journal of Buffalo Science, 1, 139-146.

https://doi.org/10.6000/1927520x.2012.01.02.02

BPS. (2017). Kuansing dalam angka. Badan Pusat Statistik. Kuansing

Ferraz, A. P., Loiola, M. V. G., Rodrigues, A. S., Lima, M. C. C., De Bittencourt, T. C. B. dos S. C., \& Filho, A. de L. R. (2017). The effect of the intensity of estrus expression on the follicular diameter and fertility of nellore cows managed under a FTAI program. Cienc. Anim. Bras, 18, 1-9. https://doi.org/10.1590/10896891v18e-37643

Gordon, I. (2017). Reproductive technologies in farm animals.CABI

Hafez, E. S. E., Jainudeen, M. R., \& Rosnina, Y. (2000). Hormones, Growth Factors, and Reproduction. In Reproduction in Farm Animals (pp. 31-54). Baltimore, Maryland, USA: Lippincott Williams \& Wilkins. https://doi.org/10.1002/978111926530 6.ch3

Hafizuddin, H., Siregar, T. N., \& Akmal, M. (2012). Hormon Dan Perannya Dalam Dinamika Folikuler Pada 
Hewan. Jesbio, 1(1), 21-24.

Hafizuddin, H., Siregar, T. N., Akmal, M., Melia, J., Husnurrizal, H., \& Armansyah, T. (2012). Perbandingan Intensitas Berahi Sapi Aceh Yang Disinkronisasi Dengan Prostaglandin F2 Alfa Dan Berahi Alam. Jurnal Kedokteran Hewan, 6(2), 81-83.

Hashemi, M., \& Safdarian, M. (2017). Efficiency of different methods of estrus synchronization followed by fixed time artificial insemination in Persian downy does. Animal Reproduction, 14(2), 413-417. https://doi.org/10.21451/1984-3143ar825

Islam, R. (2011). Synchronization of estrus in cattle: A review. Veterinary World, 4(3), 136-141. https://doi.org/10.5455/vetworld.2011. 136-141

Jamsawat, V., Mamuad, F. V, \& Venturina, E. V. (2015). Effects of PGF2 alpha and GnRH on reproductive performance of cattle and buffaloes in Thailand and Philippines. Journal of Agricultural Technology, 11(8), 2273-2281. Retrieved from http://www.ijataatsea.com/pdf/v11_n8_15_December Specialissue/071- Virapol Jamsawat -S5.pdf

Kaim, M., Bloch, A., Wolfenson, D., BrawTal, R., Rosenberg, M., Voet, H., \& Folman, Y. (2003). Effects of GnRH Administered to Cows at the Onset of Estrus on Timing of Ovulation, Endocrine Responses, and Conception. Journal of Dairy Science, 86(6), 2012-2021. https://doi.org/10.3168/jds.s00220302(03)73790-4

Keskin, A., Yilmazbas-Mecitoglu, G., Gumen, A., Karakaya, E., Darici, R., \& Okut, H. (2010). Effect of hCG vs. $\mathrm{GnRH}$ at the beginning of the Ovsynch on first ovulation and conception rates in cyclic lactating dairy cows. Theriogenology, 74(4), 602-607.

https://doi.org/10.1016/j.theriogenolo gy.2010.03.009

Komariah, K., Sumantri, S., Nuraini, H.,
Nurdiati, S., \& Mulatsih, S. (2015). Performans Kerbau Lumpur dan Strategi Pengembangannya pada Daerah dengan Ketinggian Berbeda di Kabupaten Cianjur. Jurnal Veteriner, 16(4), 606-615. https://doi.org/10.19087/jveteriner.20 15.16.4.606

Malik, A., Gunawan, A., Jaelani, A., Budirahman, R., \& Erlina, S. (2013). Comparison of Estrus Synchronization with Application of Prostaglandin F2 $\alpha$ Intrauterine and Intramuscular in Bali and CrossbredOngole Cattle. Pakistan Veterinary Journal, 33(4), 446-449. https://doi.org/10.1097/QCO.0b013e3 283638104

Malik, A., Heppy, Djaya, M. S., \& Widaningsih, N. (2018). Comparing Response of Estrus Synchronization in the Heifers and Cows on Estrus Initial, Duration of Estrus and Pregnancy Rate Bali Cattle. Advances in Animal and Veterinary Sciences, 6(6), 242-245.

Mardiansyah, Yuliani, E., \& Prasetyo, S. (2016). Respon tingkah laku birahi, service per conception, non return rate, conception rate pada Sapi Bali dara dan induk yang disinkronisasi birahi dengan hormon Progesteron. Jurnal Ilmu Dan Teknologi Peternakan Indonesia, 2(1), 134-143.

Mohammed, K. M. E. (2018). Application of advanced reproductive biotechnologies for buffalo improvement with focusing on Egyptian buffaloes. Asian Pacific Journal of Reproduction, 7(5), 193205. https://doi.org/10.4103/23050500.241177

Mufiidah, N., Ihsan, M. N., \& Nugroho, H. (2013). Produktivitas Induk Kerbau Rawa (Bubalus Bubalis) Ditinjau Aspek Kinerja Reproduksi Dan Ukuran Tubuh Di Kecamatan Tempursari Kabupaten Lumajang. Jurnal Ternak Tropika, 14(1), 21-28.

Nanda, A. S., Brar, P. S., \& Prabhakar, S. (2003). Enhancing reproductive performance in dairy buffalo: major constraints and achievements. 
Reproduction 61, 27-36. Retrieved from

http://www.ncbi.nlm.nih.gov/pubmed/ 14635924

Neglia, G., Capuano, M., Balestrieri, A., Cimmino, R., Iannaccone, F., Palumbo, F., Campanile, G. (2018). Effect of consecutive resynchronization protocols on pregnancy rate in buffalo (Bubalus bubalis) heifers out of the breeding season. Theriogenology, 113, 120126. https://doi.org/10.1016/J.

Noseir, W. M. (2003). Ovarian follicular activity and hormonal profile during estrous cycle in cows: the development of 2 versus 3 waves. Reproductive Biology and Endocrinology: $1, \quad 50$. https://doi.org/10.1186/1477-7827-150

Praharani, L., \& Sianturi, R. (2018). Tekanan Inbreeding dan Alternatif Solusi pada Ternak Kerbau. Wartazoa, 28(1), 1-12.

Purohit, G., Thanvi, P., Pushp, M., Gaur, M., Saraswat, C. S., Arora, A. S., Gocher, T. (2019). Estrus synchronization in buffaloes: Prospects, approaches and limitations. The Pharma Innovation Journal, 8(2), 54-62.

https://doi.org/10.13140/RG.2.2.3317 3.78563

Pursley, J. R., Kosorok, M. R., \& Wiltbank, M. C. (1997). Reproductive Management of Lactating Dairy Cows Using Synchronization of Ovulation. Journal of Dairy Science, 80(2), 301306.

https://doi.org/10.3168/jds.s00220302(97)75938-1

Pursley, J. R., Silcox, R. W., \& Wiltbank, M. C. (1998). Effect of Time of Artificial Insemination on Pregnancy Rates, Calving Rates, Pregnancy Loss, and Gender Ratio After Synchronization of Ovulation in Lactating Dairy Cows. Journal of Dairy Science, 81(8), 2139-2144. https://doi.org/10.3168/jds.s00220302(98)75790-x

Rizal, M., \& Riyadhi, M. (2017). Fertilitas
Semen Kerbau Rawa (Bubalus bubalis carabanensis) yang Diencerkan dengan Pengencer Nira Aren. Jurnal Veteriner, 17(3), 457-467. https://doi.org/10.19087/jveteriner.20 16.17.3.457

Saili, T., Baa, L. O., Ode, L., Sani, A., Rahadi, S., Sura, I. W., \& Lopulalan, F. (2016). Sinkronisasi Estrus dan Inseminasi Buatan Menggunakan Semen Cair Hasil Sexing pada Sapi Bali Induk Yang Dipelihara dengan Sistem yang Berbeda. Jurnal Ilmu Ternak, 16(2), 49-55.

Samsuandi, R., Sari, E. M., \& Abdullah, M. A. N. (2016). Performans Reproduksi Ke rbau Lumpur ( bubalus bubalis ) Betina di Kecamatan Simeulue Barat Kabupaten Simeulue. Jurnal Ilmiah Mahasiswa Pertanian Unsyiah, 1(1), 665-670.

Sanker, S., Kumar, D., Mandal, K. G., Taggar, R. K., \& Das, A. K. (2014). Factors influencing the dry period and calving interval in different grades of buffaloes. Buffalo Bulletin, 33(1), 120-126. https://doi.org/10.14456/kubufbu. 2014.23

Siregar, T. N., Hamdan, H., Riady, G., Panjaitan, B., Aliza, D., Pratiwi, E. F., ... Husnurrizal, H. (2015). Efficacy of Two Estrus Synchronization Methods in Indonesian Aceh Cattle. International Journal of Veterinary Science, 5(1), 44-47.

Steel, R. G. D., Torrie, J. h., \& Sumantri, B. (1991). Prinsip dan prosedur statistika: suatu pendekatan biometrik. Gramedia Pustaka Utama. Retrieved from https://books.google.co.id/books/abou t/Prinsip_Dan_Prosedur_Statistika.ht ml?id=ryUOkAEACAAJ\&redir_esc $=$ $\mathrm{y}$

Yendraliza, Y., Udin, Z., Zesfin, B., \& Jaswandi, J. (2010). Karakteristik reproduk si kerbau lumpur (swamp buffalo ) betina di kabupaten kampar. In Seminar Nasional Teknologi Peternakan dan Veteriner 2010 (pp. 68-72). Bogor.

Yendraliza, Y., Zespin, B., Udin, Z., Jaswandi, J., \& Arman, C. (2012). 
Penampilan Reproduksi Kerbau Post

Partum pada Berbagai Level GnRH yang disinkronisasi dengan PGF $2 \alpha$. JITV, 17(2), 107-111. 